\title{
Analysis of Changes in Parameters of Free Vibration of Single and Multi-span Girders with Semi-rigid Joints
}

\author{
Witold Basiński ${ }^{{ }^{*}}$ \\ ${ }^{1}$ Faculty of Civil Engineering, Silesian University of Technology, Akademicka 5, 44-100 Gliwice, Poland \\ * Corresponding author, e-mail: witold.basinski@polsl.pl
}

Received: 24 June 2021, Accepted: 19 November 2021, Published online: 25 November 2021

\begin{abstract}
This study presents the analysis carried out for changes in parameters of free vibrations of single-span corrugated web girders with a semi-rigid joint at midspan and multi-span girders with spans connected by semi-rigid joints.

Based on the experimental tests and the theoretical analysis, the behavior of six simply supported girders with the semi-rigid joint at midspan was analyzed. They were straight and double-slope girders with a span of $6.02 \mathrm{~m}$, made of corrugated web sections WTA $500 / 300 \times 15$ with different types of semi-rigid end plate joints. It was demonstrated that the variable rotational stiffness $S_{j}$ of the joint affected the equivalent concentrated mass of the girder $m_{z^{\prime}}$ the frequency of damped free vibrations $a$, damping $\rho$, and the frequency of free vibrations $\omega$.

The theoretical analysis was conducted for a change in the equivalent concentrated mass of the single-span girders fixed at both ends and of the multi-span girders. It was described how the change in the support stiffness in the single-span girders fixed at both ends and the change in joint stiffness of spans affected the equivalent concentrated mass $m_{z}$ as a function of non-dimensional stiffness $k$. The equivalent concentrated mass $m_{z}$ of the girder was found to affect the values of maximum vibrations in the structure. A continuous change in the rotational stiffness of joints was taken into account from the pinned to the rigid joint.
\end{abstract}

Keywords

free vibrations, semirigid joints, girders with corrugated web, equivalent concentrated mass

\section{Introduction}

Semi-rigid joints are crucial in analyzing structures. Eurocode 3 [1] defines three types of joints: rigid, semirigid and pinned. The development of semi-rigid joints and their effect on the whole structure have become a subject of interest of many researchers within the recent several years. Many theoretical models describing the behavior of semi-rigid joints, that is the relation $M(\phi)$, were developed on the basis of the experimental tests [2-5].

The rotational stiffness of semi-rigid joints in critical places in the girders significantly affects the critical resistance and the ultimate resistance of member structures, and consequently affects safety of the whole load bearing system. Geometry of the joint components, that is, flange and web components with bolts have an impact on the rotational stiffness. On the other hand, the deviation from the statistically determined rotational stiffness of semirigid end joints is caused by random geometrical imperfections of the joint components and the structure.
In case of the dynamic analysis, the semi-rigid joints change damping, vibration frequencies, and equivalent concentrated mass of the system $m_{z}$, which indirectly changes the integrated stiffness $K$ of both single- and multi-span girders [6-10]. Many papers [11-15] refer to the analysis of the impact of the member cross-section, damping, and rotational stiffness of joints on free vibrations of frames and beams. However, anomalies related to the girder structures are reflected by parameters of free vibrations, e.g., an increased damping indicates the possible sliding friction between joints or permanent strains in e.g., end joints [16-18]. Natural frequencies of the girders with semi-rigid joints different than expected indicate, among other things, a possible presence of joints with stiffness lower than expected, too small cross-section of the beam, and thus a change in the equivalent concentrated mass, mechanical damage to beam or joint components, or geometrical imperfections of planes of contact. 
This paper presents the analysis carried out for changes in parameters of free vibrations of single-span corrugated web girders with a semi-rigid joint at midspan and multispan girders with spans connected by semi-rigid joints.

In the case of single-span girders, the experimental tests and the theoretical analysis were used to analyze the behavior of six simply supported girders with the semirigid joint at midspan. They were straight and double-slope girders with a span of $6.02 \mathrm{~m}$, made of corrugated web sections WTA 500/300x15 with different types of semi-rigid end joints. The variable rotational stiffness $S_{j}$ of the joint was demonstrated to affect the equivalent concentrated mass of the girder $m_{z}$, the frequency of damped free vibrations $\alpha$, damping $\rho$, and the natural frequencies $\omega$. It should be noted that the corrugated web changes stiffness of the girders [19-24]. Consequently, parameters of the vibratory motion are also changed. Additionally, the impact of changed stiffness of supports in the single-span girders fixed at both ends on equivalent concentrated mass $m_{z}$, was analyzed. This parameter significantly affects the level of maximum vibrations of the structure.

In case of the multi-span girders, the theoretical analysis was conducted on the impact of semi-rigid joints between the span on a change in the equivalent concentrated mass of the girder $m_{z}$ for first three forms of vibrations as a function of the non-dimensional stiffness $k$ of the joints. A continuous change in the rotational stiffness of joints was taken into account from the pinned to the rigid joint.

\section{Theoretical methods of determining natural frequencies of beams with semi-rigid joints}

The natural vibration frequency of the girders loaded with a uniformly distributed mass $\mu$ (Fig. 1) can be presented on the basis of the method of stiffness.

In this case a differential equation of the dynamic equilibrium of the beam [9] (with a neglected damping) is expressed as:

$$
E J \frac{\partial^{4} y}{\partial x^{4}}+\mu \frac{\partial^{4} y}{\partial t^{2}}=0
$$

where: $E J$ - stiffness of the member cross-section, $\mu-$ mass per the unit of the member length.

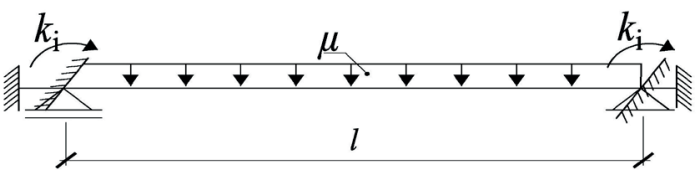

Fig. 1 Beam with semi-rigid joints at the ends with continuous distribution of mass $\mu$-stiffness method
Using the method of stiffness to solve the equation, the known matrix of dynamic stiffness of the beam component can be applied [17]:

$$
K(\lambda)=\left[\begin{array}{cccc}
\frac{E J}{l^{3}} F_{5}(\lambda) & \frac{-E J}{l^{3}} F_{6}(\lambda) & \frac{E J}{l^{2}} F_{3}(\lambda) & \frac{E J}{l^{2}} F_{4}(\lambda) \\
\frac{-E J}{l^{3}} F_{6}(\lambda) & \frac{E J}{l^{3}} F_{5}(\lambda) & \frac{-E J}{l^{2}} F_{4}(\lambda) & \frac{-E J}{l^{2}} F_{3}(\lambda) \\
\frac{E J}{l^{2}} F_{3}(\lambda) & \frac{-E J}{l^{2}} F_{4}(\lambda) & \frac{E J}{l} F_{1}(\lambda) & \frac{E J}{l} F_{2}(\lambda) \\
\frac{E J}{l^{2}} F_{4}(\lambda) & \frac{-E J}{l^{2}} F_{3}(\lambda) & \frac{E J}{l} F_{2}(\lambda) & \frac{E J}{l} F_{1}(\lambda)
\end{array}\right],
$$

where $F_{1}(\lambda)$ to $F_{6}(\lambda)$ are functions depending on the tabulated Krylov functions:

$$
\begin{aligned}
& F_{1}(\lambda)=\lambda \frac{\cosh (\lambda) \sin (\lambda)-\sinh (\lambda) \cos (\lambda)}{1-\cosh (\lambda) \cos (\lambda)}, \\
& F_{2}(\lambda)=\lambda \frac{\sinh (\lambda)-\sin (\lambda)}{1-\cosh (\lambda) \cos (\lambda)}, \\
& F_{3}(\lambda)=\frac{\lambda^{2} \sinh (\lambda) \sin (\lambda)}{1-\cosh (\lambda) \cos (\lambda)}, \\
& F_{4}(\lambda)=\lambda^{2} \frac{\cosh (\lambda)-\cos (\lambda)}{1-\cosh (\lambda) \cos (\lambda)}, \\
& F_{5}(\lambda)=\lambda^{3} \frac{\cosh (\lambda) \sin (\lambda)+\sinh (\lambda) \cos (\lambda)}{1-\cosh (\lambda) \cos (\lambda)}, \\
& F_{6}(\lambda)=\lambda^{3} \frac{\sinh (\lambda)+\sin (\lambda)}{1-\cosh (\lambda) \cos (\lambda)},
\end{aligned}
$$

in which the coefficient of natural frequencies $\lambda$ depends on the natural frequencies $\omega(4)$ :

$$
\lambda^{4}=\frac{\mu \omega^{2} l^{4}}{E J}-->\omega=\lambda^{2} \sqrt{\frac{E J}{\mu l^{4}}} .
$$

In the case of mass per the unit of the member length $\mu$, the known dynamic stiffness matrix Eq. (2) was used. Using the stiffness method, the stiffness matrices were obtained taking into account the rotational stiffness of the bars. By equating the stiffness matrix determinant to zero, the equation was obtained, from which, for the given non-dimensional stiffness parameters $k_{i}=S^{*} 1 / E J$, the natural frequency coefficient $\lambda$ was determined.

In the case of the discrete mass distribution (Fig. 2), the natural frequency is described by the motion equation in the matrix form [3]:

$B \ddot{y}+K y=0$,

where $B$ is the matrix of inertia, and $K$ is the stiffness matrix.

In the case of the force method, the solution comes down to solving the equation of natural frequency in the form [17]: 


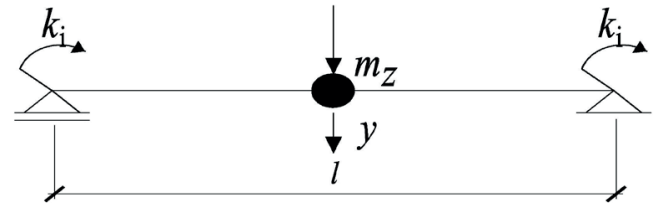

Fig. 2 Beam with semi-rigid joints at the ends with d discrete of mass distribution $m_{z}$ - force method

$\left|F B-\lambda_{s} I\right|=0$

where: $I$ - the identity matrix, $F=K^{-1}$ - flexibility matrix, $\lambda_{s}$ - the coefficient of natural frequencies in discreet model.

But the coefficient $\lambda_{s}$ dependent on the natural frequencies $\omega$ takes the following Eq. (7) [17]:

$\lambda_{s}=\frac{E J}{\omega^{2} m_{z} l^{3}}->\omega=\frac{1}{\sqrt{\lambda_{S}}} \sqrt{\frac{E J}{m_{z} l^{3}}}$.

3 Experimental tests on parameters of free vibrations of single-span girders with semi-rigid joint at midspan

\subsection{Description of test girders}

The parameters of free vibrations of six single-span girders with the semi-rigid joint at midspan were analyzed for the girders made of WTA 500/300x15 sections with the web width $t_{w}=2 \mathrm{~mm}$. The girder webs were made of steel S235, and flanges of steel 275 (Fig. 3).

Two independent pre-assembled items were specified for these girders. They were mirrored items with the end field joint in the center and at both ends to perform the tests on six single-span girders with the end joint at midspan, where the applied joint types were as follows: BP-1 - cw-cw joint (the corrugated web at both sides of the end plate) (Fig. 4(a)), BP-2 - pw-cw joint (a strip of the flat web at one side of the end plate and the corrugated web at another side of the end plate) (Fig. 4(b)), BP-3 - pw-pw joint (a strip of the flat web at both sides of the end plate) (Fig. 4(c)), and BD-1 - cw-cw joint, BD-2 - pw-cw joint, BD-3 - pw-pw joint.

The corrugated web (cw) was exchanged into strips of the flat web (pw) to change the joint stiffness in accordance with the papers $[25,26]$, which was affected by lower shear stiffness of the corrugated web which served as the support for end plates.

The first type was the straight girder BP (Fig. 3(a)), and the second one was the double-slope girder BD (Fig. 3(b)) with an inclination angle of $100^{\circ}$. The static scheme of a simply supported beam with a span of $6.02 \mathrm{~m}$ was assumed for the girders.
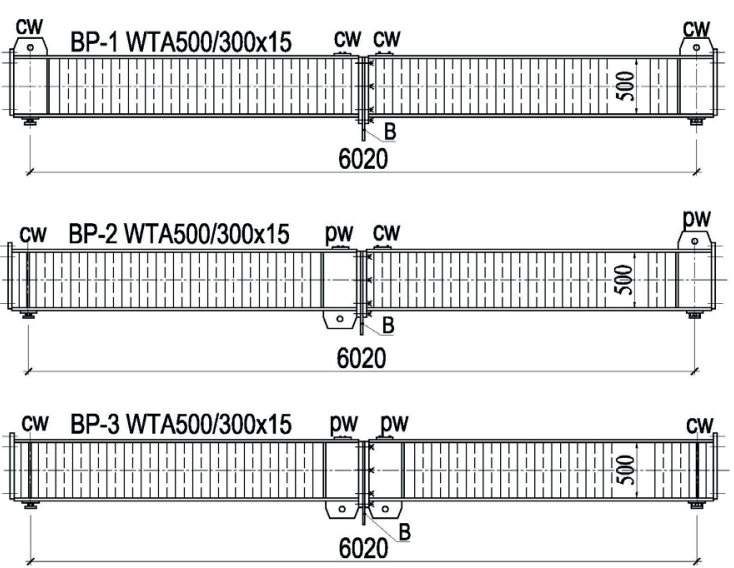

(a)

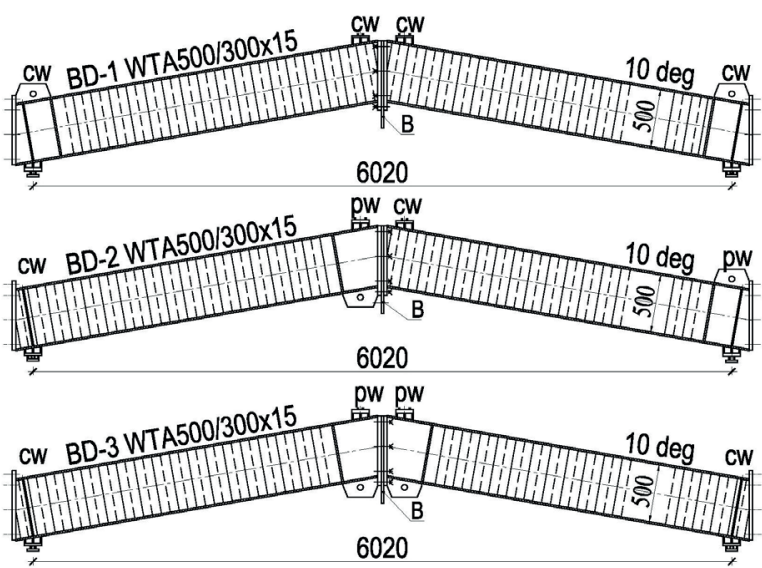

(b)

Fig. 3 Single-span girders with corrugated web a) straight girders BP-1, BP-2, BP-3; b) double-slope girders BD-1, BD-2, BD-3

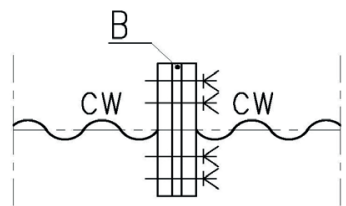

(a)

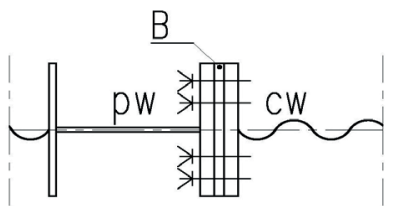

(b)

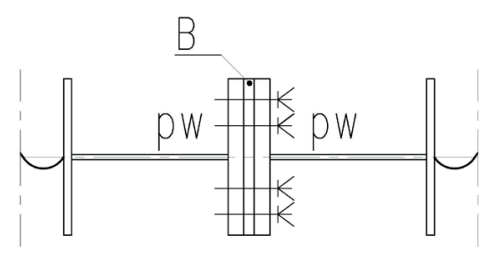

(c)

Fig. 4 Types of end - plate semirigid joint in girders: a) type cw-cw; b) type pw-cw; c) type pw-pw

The end plates of $30 \mathrm{~mm}$ in thickness were used in the semi-rigid end joints (Fig. 4). The joints were preloaded with bolts M20 of class 10.9. The packing plate placed in the middle of the end joint, marked with a letter B was 
$20 \mathrm{~mm}$ in thickness and was used to suspend the variable weight load $m_{i}$, under which vibrations were measured. The end joints were preloaded with the moment $M_{s}=120 \mathrm{Nm}$. It contributed to ca. $11 \%$ of the acceptable deformation of bolts under the load $P_{o}$ equal to $35.3 \mathrm{kN}$.

Resistance of the formed connections was higher than that of the girder section. Thus, the whole area under the imposed load met the condition of the elastic response. Edges of the end plates did not show angular deviations (Fig. 5(a)) $a 1=a 2=a 3=0 \mathrm{~mm}$ in any of the joints. As a result, the end plate joints were bolted during the free assembly without needing to tension them to eliminate clearance. On the other hand, the end plate planes in two joints of pw-cw and pw-pw types in the straight girders BP-2 and BP-3 exhibited a tendency for the curved deviation $a 4$ as shown in Fig. 5(b).

\subsection{Experimental test}

All the girders tested (1) were placed on (movable and fixed) bearings (2) that were put on rigid reinforced concrete columns (3) (Fig. 6).

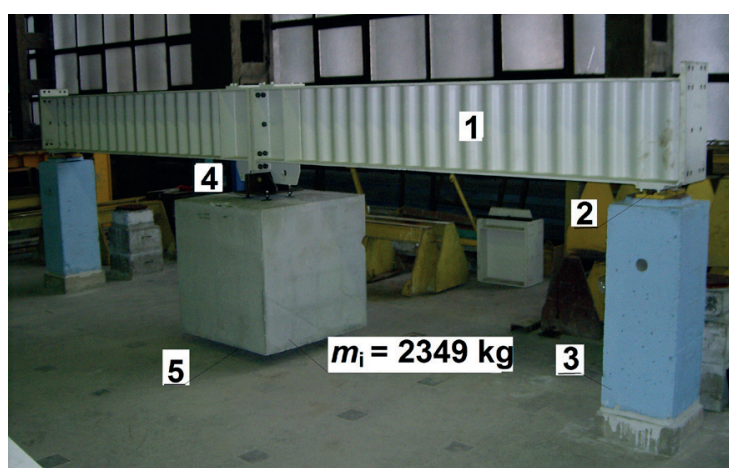

(a)

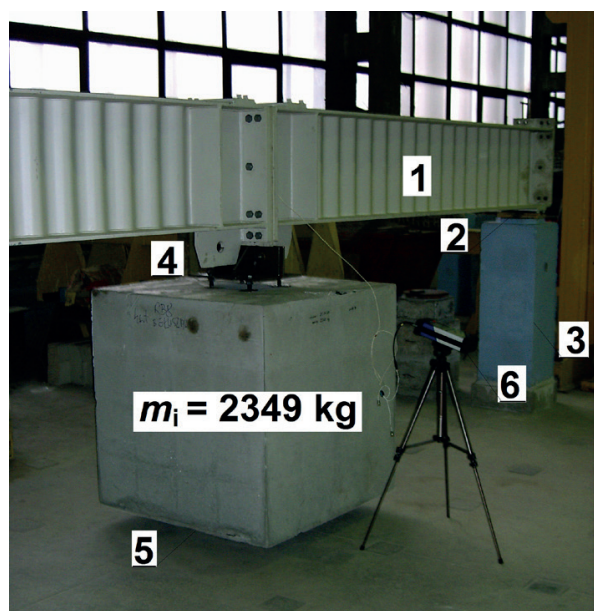

(c)

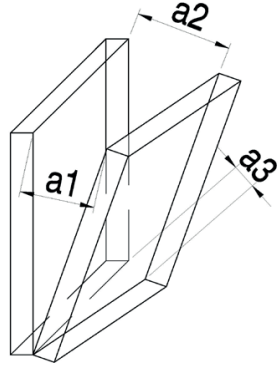

(a)

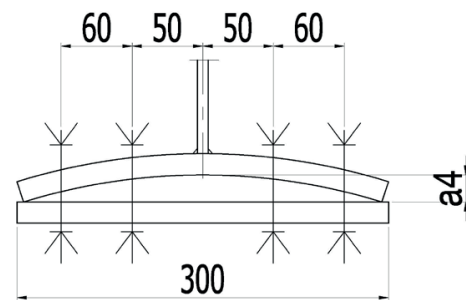

(b)
Fig. 5 Deviation of end plates: a) edge deviations; b) deviations at the pw-cw and pw-pw joints in girders BP-2 and BP-3

Three different concentrated masses $m_{i}=421 \mathrm{~kg} ; 1218$ $\mathrm{kg}$ and $2349 \mathrm{~kg}$ were attached one by one to the girders to measure parameters of damped free vibrations. These masses were attached using the plate B and the fixing system made of angle profiles (4).

Parameters of vibrations of the single-span girders with the semi-rigid joint were tested and recorded by rapid elimination of the support (5) which carried each subsequent concentrated mass $m_{i}$, and the introduction of a short dynamic impulse. The support was a $\phi 50$ tube ended with

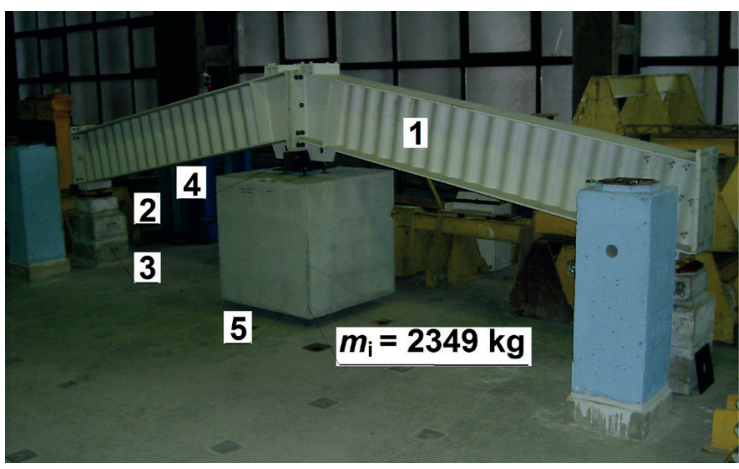

(b)

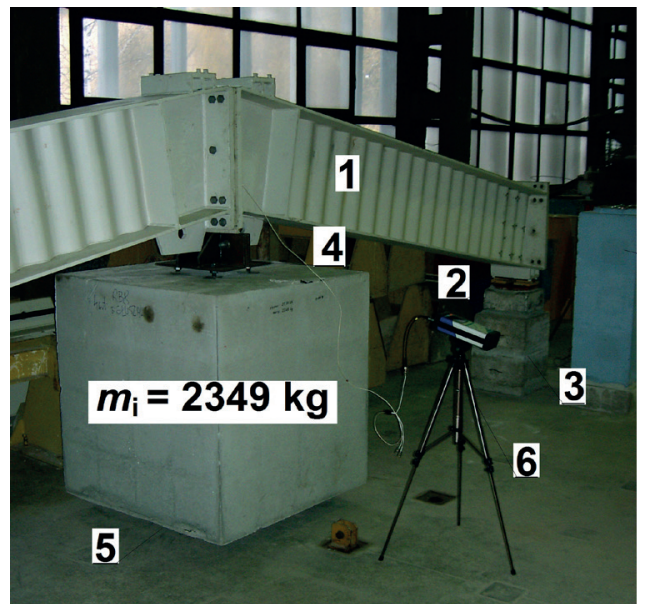

(d)

Fig. 6 Girders on the test stand with suspended concentrated mass $m_{i}=2349 \mathrm{~kg}$ : a) BP-3; b) BD-3; c) and d) BP-3 and BD-3 during measurement vibrations 
a $30 \mathrm{~mm}$ diameter steel ball. The tube went through a floor and was directly under the concentrated mass $m_{i}$.

The SVAN 912 AE vibration analyzer (6) was used to measure free vibrations in the system of girders with the concentrated mass $m_{i}$. The transducer in the vibration analyzer was placed in the central part of the joint at the edge of the corrugated or flat web. The following parameters were measured: the amplitude of displacements, acceleration and frequency of damped vibrations which were loaded in the SvanPc software. The parameters of free vibrations at each concentrated mass $m_{i}$ were measured five times.

The effect of joint stiffness in the simply supported beam with the semi-rigid joint at midspan on the parameters of free vibrations were noticed at the first mode of vibrations. However, as the SVAN 912 AE vibration analyzer records the whole spectrum of frequencies of the structure tested, it was necessary to select the first mode of vibrations. In the case of single-span girders with the semi-rigid end joint, the first mode of vibrations corresponded to the searched frequency of damped free vibrations in the system of girder-concentrated mass. The maximum acceleration was observed for this specific first mode of vibrations. The angular frequency was selected from the whole spectrum of frequencies (Fig. 7). This frequency corresponded to the angular frequency of damped free vibrations.

Fig. 8 illustrates the recorded amplitude envelope $A_{i}$ of free vibrations in the single-span girder BP-3 with the p-p joint and the concentrated mass $2349 \mathrm{~kg}$. Table 1 lists the mean frequencies of damped free vibrations $\alpha_{s r}$ based on the tests performed. The scatter of the results was very small. Hence, the standard deviation during the measurements ranged from 0.013 for the mass $m_{t}=418 \mathrm{~kg}$ to 0.05 for the mass $m_{t}=2349 \mathrm{~kg}$.

The effect of variable rotational stiffness $S$ of individual types of joints in the test single-span girders on the equivalent concentrated mass of the girder $m_{z}$, damping $\rho$, and the natural frequency is discussed in the next section.

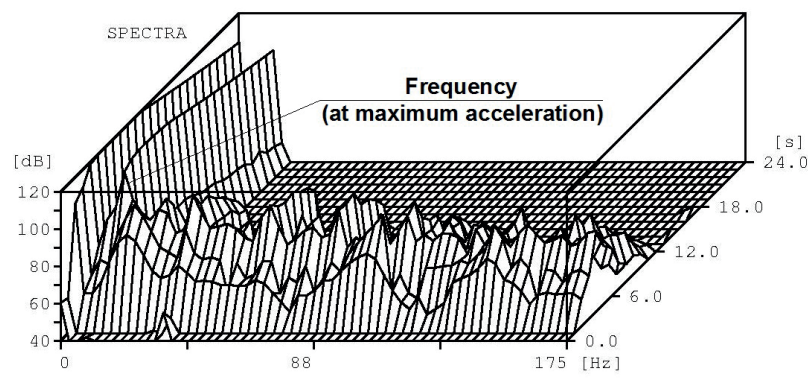

Fig. 7 The frequency spectrum of damped free vibration for the BP-3 girder with a suspended concentrated mas $m_{i}=2349 \mathrm{~kg}$

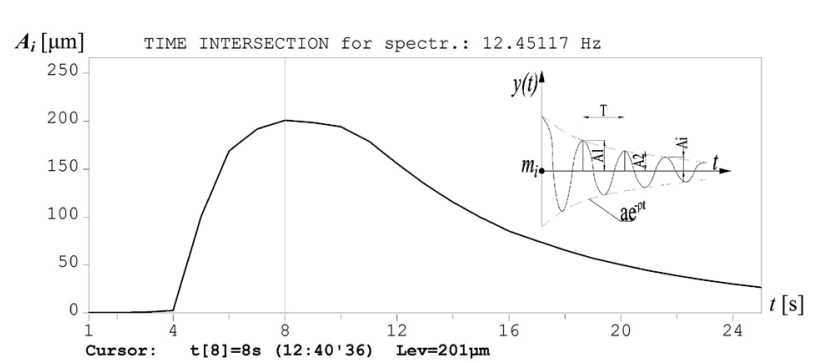

Fig. 8 The envelope of the amplitudes of the displacements A of the damped free vibrations of the BP-3 girder with a suspended concentrated mas $m_{i}=2349 \mathrm{~kg}$

Table 1 Mean frequencies of damped free vibrations $\alpha_{a v}$

\begin{tabular}{lccc}
\hline $\begin{array}{l}\text { Concentrated } \\
\text { mass } m_{i}[\mathrm{~kg}]\end{array}$ & $\begin{array}{c}\alpha_{a v} \\
{[\mathrm{rad} / \mathrm{s}]}\end{array}$ \\
\hline 421 & $\mathrm{BP}-1 / \mathrm{cw}-\mathrm{cw}$ & $\mathrm{BP}-2 / \mathrm{pw}-\mathrm{cw}$ & $\mathrm{BP}-3 / \mathrm{pw}-\mathrm{pw}$ \\
1218 & 128.8493 & 139.2542 & 139.2542 \\
2349 & 92.0361 & 101.241 & 101.241 \\
& 70.1580 & 77.7921 & 78.2319 \\
421 & $\mathrm{BD}-1 / \mathrm{cw}-\mathrm{cw}$ & $\mathrm{BD}-2 / \mathrm{pw}-\mathrm{cw}$ & $\mathrm{BD}-3 / \mathrm{pw}-\mathrm{pw}$ \\
1218 & 133.4549 & 133.4549 & 133.4549 \\
2349 & 96.6417 & 96.6417 & 96.6417 \\
\hline
\end{tabular}

It should be mentioned that a difference in frequency between damped free vibrations and free vibrations was minimal due to low material damping in steel structures. For the properly pre-loaded connections, the damping effect on the vibration frequency was minimal. Damping caused by a lack of contact between the end plates and by the displacements of joints was observed only in the case of defective connections, e.g., with loose screws.

For the control purposes, the rotational stiffness $S$ was additionally determined on the basis of measured opening of the cw-cw joints in the test girders BP-1 and BD-1 (see Fig. 9).

4 Analyzed parameters of free vibrations in single-span girders with semi-rigid joints at midspan

4.1 The effect of stiffness of the semi-rigid joint on a change in the equivalent concentrated mass $m_{z}$ of a single-span girder with the semi-rigid joint

A value of the equivalent concentrated mass $m_{z}$ expressed as the product of the distributed mass of the beam $\mu$ and its span $l$ is important for determining the vibration frequency in the discrete systems. It directly affects the natural frequency in the system $\omega$. For the single-span girder with the semi-rigid joint at midspan, the limit value of the equivalent concentrated mass $m_{z}$ for the pure hinge at the 


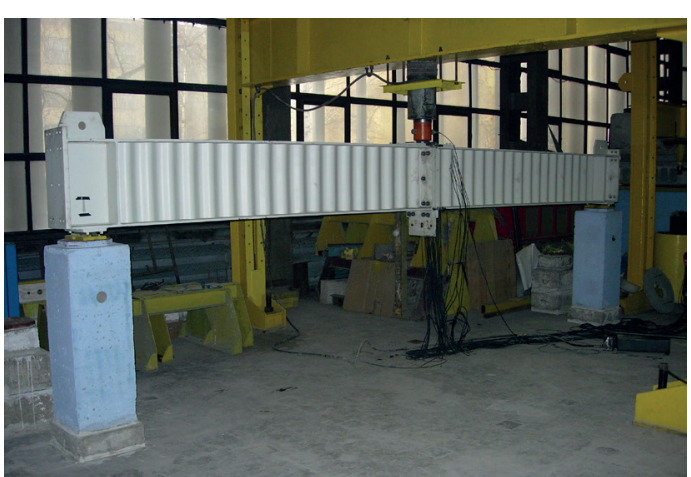

(a)

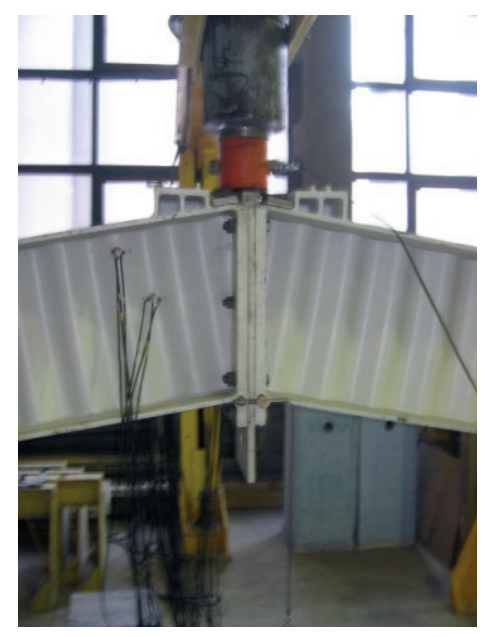

(b)

Fig. 9 The girders on the test stand during the measurement of the contact opening: a) BP-1; b) BD-1

girder midspan is $\infty$. And the connection of the full stiffness corresponds to the equivalent concentrated mass of the simply supported beam $m_{z}=17 / 35 \mu$.

Simplified models were used to determine the equivalent concentrated mass. The shear stiffness of the girder has been neglected. This leads to a slight underestimation of the equivalent value of the concentrated mass. However, it does not affect the global nature of the change of the equivalent concentrated mass associated with the change in connection stiffness. It also does not substantially affect the free vibration parameters of the tested girders with the applied concentrated masses.

Intermediate values of the equivalent concentrated mass $m_{z}$ which depend on a change in stiffness of the semi-rigid joint $S$ at midspan of the single-span girders were determined to compare changes in the coefficient of natural frequency $\lambda$. The coefficients were calculated from the method of stiffness at the continuous mass distribution $\mu$ (Fig. 10(a)) and from the force method at the discrete mass distribution $m_{z}$ (Fig. 10(b)).

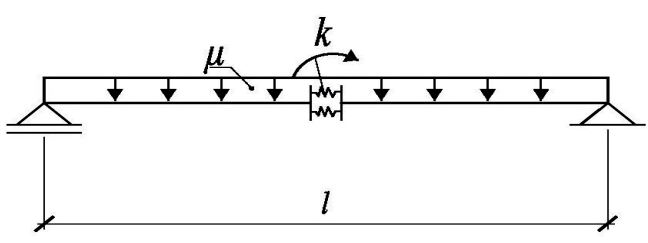

(a)

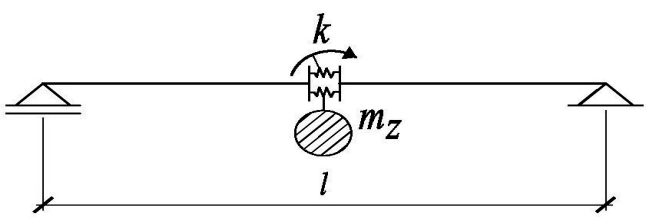

(b)

Fig. 10 A single-span girder with semi-rigid joint: a) continuous mass distribution; b) discrete mass distribution

The global matrix of dynamic stiffness $K 1$ was created for the method of stiffness on the basis of the identity matrices of rotations and displacements of individual members in the single-span girder by attributing the stiffness parameter $k$ to the semi-rigid joint. It was assumed the symmetry of the vibration mode. Hence, as a result of aggregation of the identity matrix to the global matrix, the multipliers of the $F$ function were obtained, respectively, 0.5 and 0.25 , as well as the value of $2 k$. The adopted assumptions made it possible to search for eigenvalues depending on the parameter $\lambda$. The global matrix $K 1$ takes the following form Eq. (8):

$$
K 1(\lambda)=\left[\begin{array}{cccc}
0.5 F_{1}(\lambda) & 0.5 F_{2}(\lambda) & 0 & -0.25 F_{4}(\lambda) \\
0.5 F_{2}(\lambda) & F_{1}(\lambda) & 0.5 F_{2}(\lambda) & -0.5 F_{3}(\lambda) \\
0 & 0.5 F_{2}(\lambda) & 0.5 F_{1}(\lambda) & -0.25 F_{4}(\lambda) \\
-0.25 F_{4}(\lambda) & -0.5 F_{3}(\lambda) & -0.25 F_{4}(\lambda) & 0.25 F_{5}(\lambda)+2 k
\end{array}\right]
$$

where:

$k=S l / E J$

is the non-dimensional parameter of the rotational stiffness dependent on the rotational stiffness $S$ of the joint at the girder midspan contained within the range 0 (a hinge ) $<k<\infty$ (a rigid joint).

When the determinant of the matrix of dynamic stiffness in the girder (Fig. 10(a)) was compared to zero, the following equation was obtained:

$$
\begin{aligned}
& 0.5 k F_{1}^{3}(\lambda)-0.0625 F_{1}^{2}(\lambda) F_{4}^{2}(\lambda)-0.0625 F_{1}^{2}(\lambda) F_{3}^{2}(\lambda) \\
& +0.0625 F_{1}^{3}(\lambda) F_{5}(\lambda)-0.5 k F_{1}(\lambda) F_{2}^{2}(\lambda) \\
& -0.0625 F_{1}(\lambda) F_{2}^{2}(\lambda) F_{5}(\lambda) \\
& +0.125 F_{1}(\lambda) F_{2}(\lambda) F_{3}(\lambda) F_{4}(\lambda)=0 .
\end{aligned}
$$


At the defined non-dimensional parameter of rotational stiffness $k$, the coefficient of natural frequency $\lambda^{2}$ in the single-span girder with the semi-rigid joint at midspan was determined from the Eq. (10).

Using the force method (Fig. 10(b)) the equation describing the first frequency of free vibrations $\omega$ and the coefficient $\lambda_{s}$ of natural frequencies was worked out on the basis of the flexibility matrix. This equation depended on the non-dimensional parameter of the semi-rigid joint stiffness $k$ in the girder:

$\omega(k)=\sqrt{\frac{48 k}{k+3}} \sqrt{\frac{E J}{m_{z} l^{3}}}$,

$\frac{1}{\sqrt{\lambda_{S}}}=\sqrt{\frac{48 k}{k+3}}$.

The equivalent concentrated mass $m_{z}$ dependent on the non-dimensional parameter of rotational stiffness $k$ of the semi-rigid joint, was obtained on the basis of a comparison of the vibration of natural frequencies from the stiffness method and the force method:

$m_{z}=\frac{1}{\lambda_{S} \lambda^{4}} \mu l$

The formula of a change in the equivalent concentrated mass $m_{z}$ as a function of the non-dimensional parameter of the joint stiffness $k$ in the single-span girder is illustrated in Fig. 11. This graph clearly indicates that even the minimum stiffness of the semi-rigid joint at the girder midspan at $k=0.02$ reduced the equivalent concentrated mass to $67 \%$. At the stiffness $k=6$, the concentrated mass reached $m_{z}=0.50 \mu \mathrm{l}$ which was close to the value for the simply supported continuous beam.

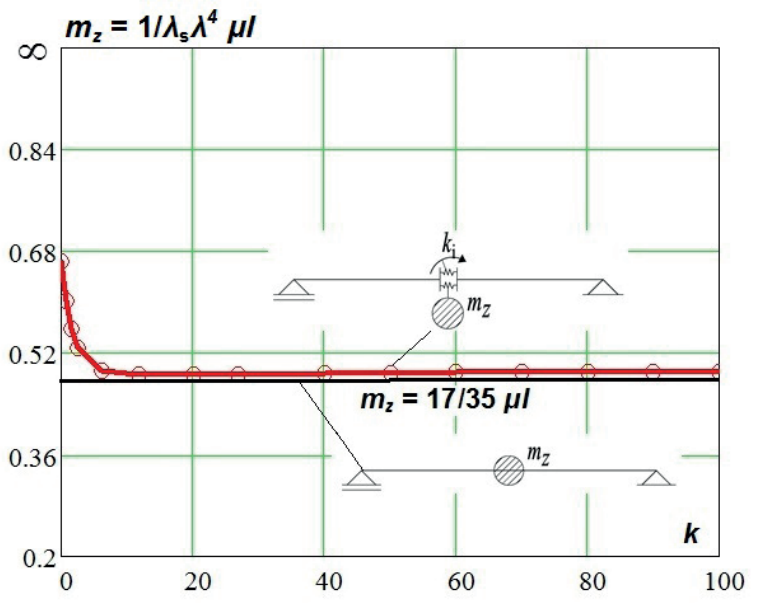

Fig. 11 Change of the equivalent concentrated mass $m_{z}$ into a singlespan girder with a semirigid joint vs stiffness $k$

\subsection{The effect of semi-rigid joint stiffness on a change} in the vibration frequencies in single-span girders

As the distribution of the equivalent concentrated mass was known, the effect of the variable rotational stiffness $S_{j}$ in the joint on damping $\rho$ and the natural frequency $\omega$ in the single-span girder with the corrugated web and the semi-rigid joint at midspan was demonstrated.

Based on the measured frequencies of damped free vibrations, the damping value $\rho$ and the natural frequencies $\omega$ in the test single-span girders with the semi-rigid joints were determined using the known equations [10]:

- oscillatory period $T=\frac{2 \pi}{\alpha}$,

- logarithmic decrement of damping $\Delta=\ln \frac{A_{i}}{A_{i+1}}=\rho T$,

- natural frequency $\omega=\sqrt{\alpha^{2}+\rho^{2}}$,

where: $A_{i}$ - subsequent amplitude of displacement.

Table 2 presents the mean damping values $\rho_{a v}$ and the natural frequencies $\omega_{a v}$ in the single-span girder with the corrugated web and the semi-rigid joint at midspan. These data were obtained from the tests.

The measured damped free vibrations with the corrugated web girders with the semi-rigid joints at midspan were used to determine damping $\rho$, which was found to be minimal. It demonstrated a significant stiffness $S$ in the joints present in the girders and a lack of damping caused by. e.g., loose screws.

The rotational stiffness of the joint in the single-span girder simultaneously affected a change in the equivalent concentrated mass $m_{z}$ and a change in the natural frequencies $\omega$. Knowing the interrelation between the stiffness $S$, the natural frequency $\omega$ and the equivalent concentrated mass $m_{z}$, we can draw a diagram of $\omega(k)$. To determine the accurate value of the equivalent concentrated mass of the girder $m_{z}$, the rotational stiffness values $S$ were used. These values were determined for the control purposes using the measured opening of the $\mathrm{cW}-\mathrm{cw}$ joints in the test girders BP-1 and BD-1.

Stiffness obtained for the joints tested was equal to $129 \mathrm{MNm} / \mathrm{rad}$ and $221 \mathrm{MNm}$ respectively, which corresponded to the non-dimensional coefficients of stiffness $k=6$ and 10. At such a stiffness, the equivalent concentrated mass was $m_{z}=(0.50-0.49) \mu \mathrm{l}$. Since other joints had flat sheet in the contact area, and consequently higher stiffness, the equivalent concentrated mass of the girder $m_{z}=0.49 \mu \mathrm{l}$ was taken in further tests for all the girders. It generally corresponded to the equivalent concentrated mass of the simply supported beam. 
Table 2 Mean damping frequencies $\rho_{a v}$ logarithmic decrement of damping $\Delta$, natural vibrations $\omega_{a v}$ from the tests

\begin{tabular}{|c|c|c|c|c|c|c|c|c|c|}
\hline $\begin{array}{l}\text { Concentrated } \\
\text { mass } m_{i}[\mathrm{~kg}]\end{array}$ & $\omega_{a v}[\mathrm{rad} / \mathrm{s}]$ & $\rho_{a v}[\mathrm{rad} / \mathrm{s}]$ & $\Delta$ & $\omega_{a v}[\mathrm{rad} / \mathrm{s}]$ & $\rho_{a v}[\mathrm{rad} / \mathrm{s}]$ & $\Delta$ & $\omega_{a v}[\mathrm{rad} / \mathrm{s}]$ & $\rho_{a v}[\mathrm{rad} / \mathrm{s}]$ & $\Delta$ \\
\hline & \multicolumn{3}{|c|}{ BP-1/ cw-cw } & \multicolumn{3}{|c|}{$\mathrm{BP}-2 / \mathrm{pw}-\mathrm{cw}$} & \multicolumn{3}{|c|}{ BP-3/pw-pw } \\
\hline 421 & 128.8496 & 0.2757 & 0.0134 & 139.2545 & 0.2629 & 0.0119 & 139.2545 & 0.2464 & 0.0111 \\
\hline 1218 & 92.0364 & 0.2316 & 0.0158 & 101.2411 & 0.1531 & 0.0095 & 101.2411 & 0.1351 & 0.0084 \\
\hline \multirow[t]{2}{*}{2349} & 70.1583 & 0.1753 & 0.0157 & 77.7922 & 0.1319 & 0.0107 & 78.2320 & 0.1198 & 0.0096 \\
\hline & \multicolumn{3}{|c|}{ BD-1/cw-cw } & \multicolumn{3}{|c|}{$\mathrm{BD}-2 / \mathrm{pw}-\mathrm{cw}$} & \multicolumn{3}{|c|}{ BD-3/pw-pw } \\
\hline 421 & 133.4556 & 0.4464 & 0.0196 & 133.4550 & 0.1768 & 0.0083 & 133.4550 & 0.1477 & 0.0066 \\
\hline 1218 & 96.6422 & 0.3160 & 0.0182 & 96.6419 & 0.1904 & 0.0124 & 96.6418 & 0.1322 & 0.0087 \\
\hline 2349 & 73.5826 & 0.1655 & 0.0132 & 74.2611 & 0.1578 & 0.0133 & 74.9523 & 0.1499 & 0.0126 \\
\hline
\end{tabular}

The force method was applied to determine the natural frequencies $\omega$, which depended on the non-dimensional stiffness parameter $k$ for the single-span girders with the semirigid joint at midspan. As the girder web was relatively thin, the shear stiffness was included in the flexibility matrix. The natural frequency $\omega$ dependent upon the non-dimensional stiffness parameter $k$ was described by the equation:

$$
\omega(k)=\sqrt{\frac{1}{\frac{m_{t} l^{3}}{16 E J k}+\frac{m_{t} l^{3}}{48 E J}+\eta \frac{m_{t} l}{4 G A}}},
$$

where: $m_{t}=m_{i}+m_{z}+m_{a}-$ total concentrated mass of the system, which includes the suspended mass load $m_{i}$, the equivalent concentrated mass of the girder $m_{z}$, and additionally the mass $m_{a}$, that is, the mass of screws, end plates, the packing plate B and the angle profile sling (4), $\eta$ - shear coefficient for the corrugated web girders equal to 11.484 [25], $G A$ - shear stiffness of the girder member.

The formula for a change in the natural frequencies $\omega$ as a function of the non-dimensional stiffness parameter $k$ of the joint at the suspended concentrated mass $m_{i}=2349 \mathrm{~kg}$ of the single-span girders BP-1, 2 and 3 is presented in Fig. 12(a), and of the girders BD -1, 2 and 3 is shown in Fig. 12(b). The illustrated rotational stiffness values of joints were based on the values described in the paper [6].

The character of curves indicates that at the beginning the angular natural frequency was suddenly changed at even slightly increased stiffness. This is natural as there is a transition between the mechanism and the continuous beam in this area. Then, the change was gentle and approached at an increasing stiffness of the joints the constant value typical for the continuous beam.

Replacing the corrugated web with strips of the flat one caused a slight increase in both the joint stiffness and the natural frequencies (Fig. 12). However, the biggest change in the natural frequencies at a large increase in the stiffness

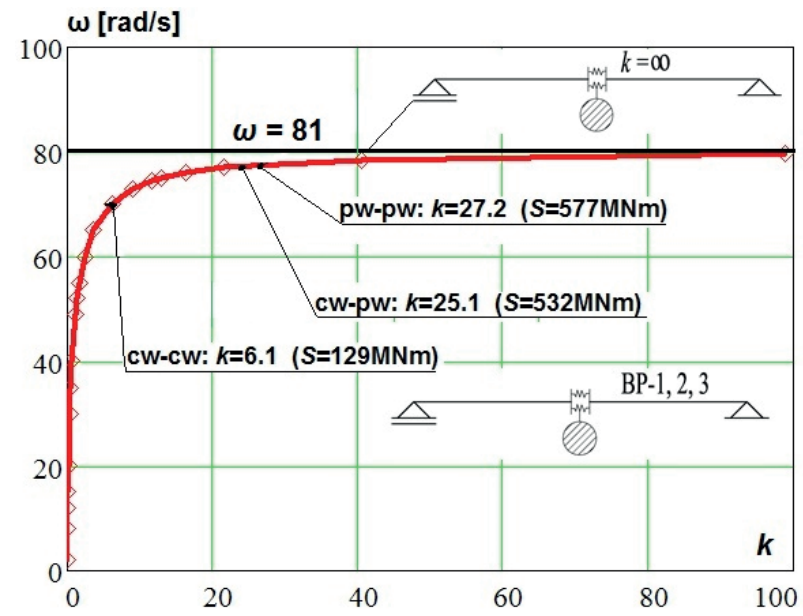

(a)

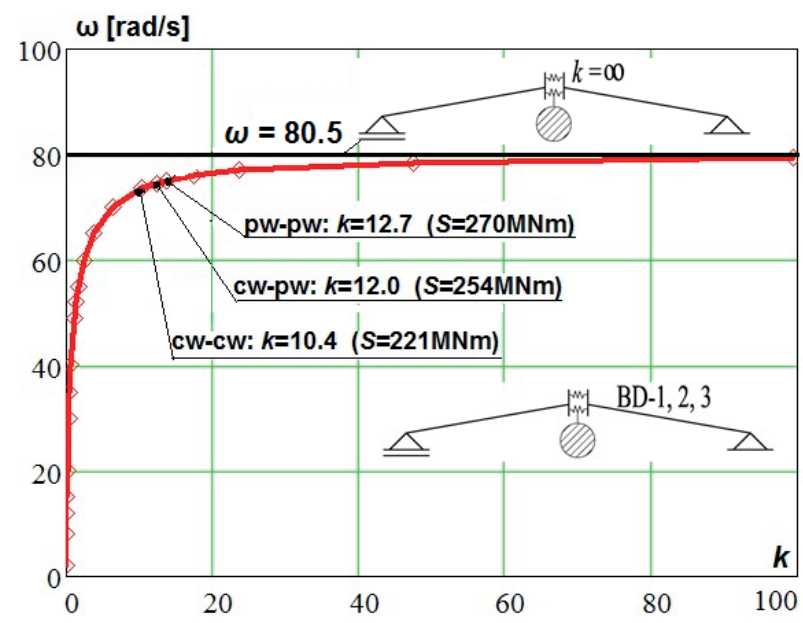

(b)

Fig. 12 The formula $\omega(k)$ of single-span girders with corrugated web with semi-rigid joint in the middle of the span: a) girders BP-1, 2, 3; b) girders BD-1, 2, 3

was caused by preloading of geometrically imperfect end plates in pw-cw and pw-pw joints in the straight beam (Fig. 5(b)) It was found to be desirable due to stiffness of the joints. On the other hand, a resulting increase forces in the bolts had a negative impact on their resistance. 


\section{The effect of rotational stiffness of supports in the} girders fixed at both ends on a change in the equivalent concentrated mass $\boldsymbol{m}_{z}$

When both ends of the single-span girders were fixed semi-rigid, a change in the rotational stiffness of these joints also changed the natural frequencies. This change also caused a change in the equivalent concentrated mass within a range constrained by the simply supported beam scheme at $m_{z}=17 / 35 \mu$ land by rigidly fixed beam scheme at $m_{z}=13 / 35 \mu 1$. Thus, the variation interval was much more constrained than for the girder with the semi-rigid joint at midspan as the mechanism could not be formed.

The relationship for the equivalent concentrated mass as a function of non-dimensional stiffness parameters of the support fixings could be developed by comparing the natural frequencies $\lambda$ determined by the method of stiffness at the continuous mass distribution $\mu$ (Fig. 13(a)) and by the force method at the discrete mass distribution $m_{z}$ (Fig. 13(b)).

In the method of stiffness, the global matrix of dynamic stiffness $K 2$ which covered the stiffness parameter $k_{1}$ and $k_{2}$ of the supports, takes the following form Eq. (18):

$$
K 2(\lambda)=\left[\begin{array}{cc}
F_{1}(\lambda)+k_{1} & F_{2}(\lambda) \\
F_{2}(\lambda) & F_{1}(\lambda)+k_{2}
\end{array}\right],
$$

where:

$$
k_{1}=S_{1} l / E J \text { and } k_{2}=S_{2} l / E J
$$

are the non-dimensional parameters of the rotational stiffness dependent on the rotational stiffness $S_{1}$ and $S_{2}$ of semirigid supports contained within the range 0 (a hinge) $<k<\infty$ (a rigid joint).

When the determinant of the matrix of dynamic stiffness in the girder fixed at both side (Fig. 13(a)) was compared to zero, the following equation was obtained Eq. (20):

$F_{1}^{2}(\lambda)-F_{2}^{2}(\lambda)+k_{1} k_{2}+k_{1} F_{1}(\lambda)+k_{2} F_{1}(\lambda)=0$.

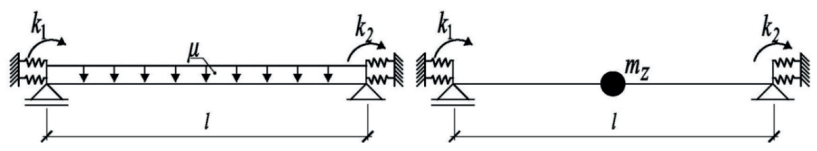

(a)

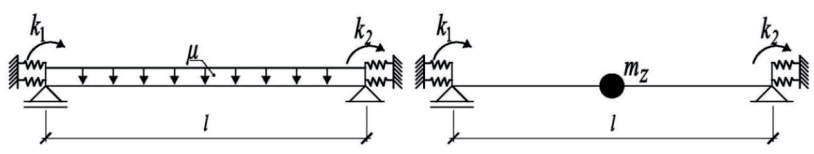

(b)

Fig. 13 A girder fixed semi-rigid on both ends: a) continuous mass distribution; b) discrete mass distribution
At the defined non-dimensional parameter of rotational stiffness $k_{1}$ and $k_{2}$, the coefficient of natural frequencies $\lambda^{2}$ in the single-span girder with the semi-rigidly joined supports was determined from the Eq. (20).

Using the force method (Fig. 13(b)) the equation describing the first frequency of free vibrations $\omega$ and the coefficient $\lambda_{s}$ of natural frequencies was worked out on the basis of the flexibility matrix. This equation depended on the non-dimensional parameters of the rotational stiffness $k_{1}$ and $k_{2}$ in joints of the girder supports.

$$
\begin{aligned}
& \omega(k)=\frac{1}{\left(\frac{7 k_{1}+7 k_{2}+k_{1} k_{2}+48}{768 k_{1}+768 k_{2}+192 k_{1} k_{2}+2304}\right)^{0.5}} \sqrt{\frac{E J}{m_{z} l^{3}}} \\
& \frac{1}{\sqrt{\lambda_{S}}}=\frac{1}{\left(\frac{7 k_{1}+7 k_{2}+k_{1} k_{2}+48}{768 k_{1}+768 k_{2}+192 k_{1} k_{2}+2304}\right)^{0.5}}
\end{aligned}
$$

The equivalent concentrated mass $m_{z}$, depended on the non-dimensional parameters of rotational stiffness $k_{1}$ and $k_{2}$ of the semi-rigidly joined supports in the single-span girder, was determined by comparing the natural frequencies obtained by the displacement method and the force method in accordance with the Eq. (13).

The formula of a change in the equivalent concentrated mass $m_{z}$ as a function of the non-dimensional parameter of the joint stiffness in the single-span girder fixed at both ends is illustrated in Fig. 14. For the girder fixed at both ends with semi-rigid joints, a change in the equivalent concentrated mass $m_{z}$ was included in a very narrow range of $13 / 35 \mu \mathrm{l}<m_{z}<17 / 35 \mu \mathrm{l}$ (from the rigidly fixed at the both ends at the joint stiffness $k_{1}=k_{2}=$ to the simply supported

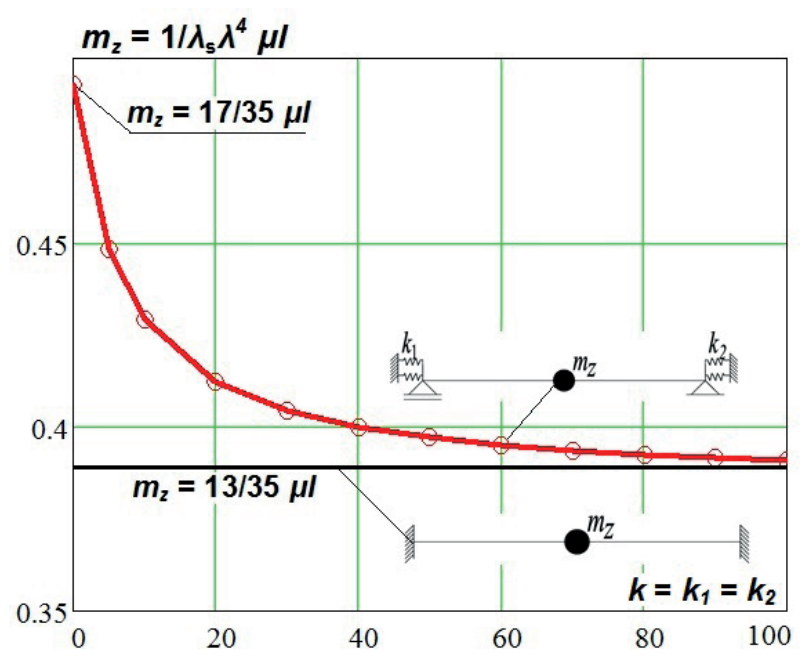

Fig. 14 Change of the equivalent concentrated mass $m_{z}$ into a singlespan girder fixed with a semirigid on both ends vs stiffness $k$ 
beam at the joint stiffness $k_{1}=k_{2}=0$ ). The equivalent concentrated mass was changing relatively slowly within this narrow range. However, at the joint stiffness $k_{1}=k_{2}=10$ the equivalent concentrated mass $m_{z}$ reached the value of $0.429 \mu \mathrm{l}$ which constituted a half of the range of the change interval, and then reached the value $0.412 \mu \mathrm{l}$ at the stiffness $k_{1}=k_{2}=20$ A further change was slow and only at the joint stiffness $\mathrm{k}=k_{1}=k_{2}=100$ it reached the limit value corresponding to the full stiffness of the supports.

\section{The effect of span flexibility in the multi-span girders on a change in the equivalent concentrated mass $\boldsymbol{m}_{z}$}

Multi-span girders are often used as purlins in hall buildings or as load-bearing elements in bridges. Therefore, they are subjected to the action of variable loads causing natural vibrations. An important issue is the assessment of the value of the equivalent concentrated mass of individual spans of the girder, which directly affects the natural frequency $\omega$ of the system. This applies in particular to multispan girders with spans semi-rigid connected on supports, where a change in the rotational stiffness of the span connections leads to a change in the natural frequency.

Therefore, the change in the value of the equivalent concentrated mass of three-span girders of constant stiffness $E J$ with semi-rigid connected spans was analyzed. It is known that in the case of three-span girders the first frequency of vibrations is constant [17]. Thus, the determination of intermediate values of the equivalent concentrated mass $m_{z}$ was performed for the second and the third mode of vibrations dependent on the change in the stiffness of the connections of the spans of the three-span girders. Determination of the intermediate values of the equivalent concentrated mass $m_{z}$ enables the comparison of the changes in the natural frequency calculated with the continuous mass distribution (Fig. 15(a)) and with the discrete mass distribution (Fig. 15(b)).

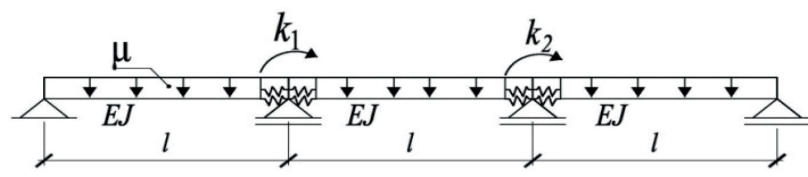

(a)

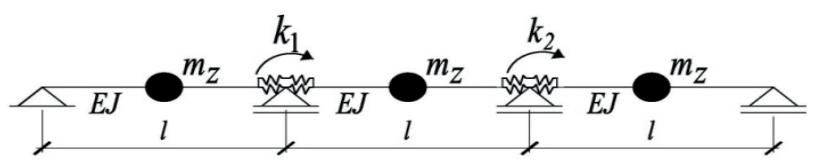

(b)

Fig. 15 A three-span girder with semi-rigid joint connected spans: a) continuous mass distribution; b) discrete mass distribution
In the case of the stiffness method with continuous mass distribution, as a result of aggregation of the unit matrices to the global matrix, the multipliers of the function $F$ were obtained, respectively, 1 and 2 . Therefore, the global dynamic stiffness matrix $K 3$ taking into account the stiffness parameters $k_{1}$ and $k_{2}$ of the semi-rigid connection of spans takes the following form Eq. (23):

$K 3(\lambda)=\left[\begin{array}{cccc}F_{1}(\lambda) & F_{2}(\lambda) & 0 & 0 \\ F_{2}(\lambda) & 2 F_{1}(\lambda)+k_{1} & F_{2}(\lambda) & 0 \\ 0 & F_{2}(\lambda) & 2 F_{1}(\lambda)+k_{2} & F_{2}(\lambda) \\ 0 & 0 & F_{2}(\lambda) & F_{1}(\lambda)\end{array}\right]$,

where $k_{1}$ and $k_{2}$ are non-dimensional parameters of the rotational stiffness which depend on the rotational stiffness $S_{1}$ and $S_{2}$ of the semi-rigid joints between spans. The non-dimensional stiffness parameters $k_{1}$ and $k_{2}$ were within the range of 0 (a hinge) $<k<$ (the continuous connection between the spans).

When the determinant of the matrix of dynamic stiffness in the three-span girder with the continuous mass distribution (Fig. 15(a)) was compared to zero, the following equation was obtained Eq. (24):

$$
\begin{aligned}
& 2 k_{1} F_{1}^{3}(\lambda)-5 F_{1}^{2}(\lambda) F_{2}^{2}(\lambda)+2 k_{2} F_{1}^{3}(\lambda)+4 F_{1}^{4}(\lambda)+ \\
& F_{2}^{4}(\lambda)-k_{1} F_{1}(\lambda) F_{2}^{2}(\lambda) \\
& -k_{2} F_{1}(\lambda) F_{2}^{2}(\lambda)+k_{1} k_{2} F_{1}^{2}(\lambda)=0 .
\end{aligned}
$$

As each of three spans in the discrete system had the concentrated mass, the system was characterized by three degrees of dynamic freedom. Consequently, the coefficients of the frequency of 1,2 and 3 mode of vibrations had to be determined. At the defined non-dimensional parameters of rotational stiffness $k_{1}$ and $k_{2}$, the coefficient of natural frequencies $\lambda^{2}$ in the three-span girder with the semi-rigidly joined supports was determined from the Eq. (24).

On the other hand, the method of forces at the discrete mass distribution (Fig. 15(b)) used the flexibility matrix to work out the equations for the first $\omega_{1}(k)$, second $\omega_{2}(k)$ and third $\omega_{3}(k)$ modes of the natural frequency and the coefficients $\lambda_{S 1,2,3}$ of natural frequencies depending on the non-dimensional stiffness parameters $k_{1}$ and $k_{2}$ of the span connections:

$$
\begin{aligned}
& \omega_{1,2,3}(k)=\frac{1}{\sqrt{\lambda_{S_{1,2,3}}}} \sqrt{\frac{E J}{m_{z} l^{3}}}, \\
& \frac{1}{\sqrt{\lambda_{S_{1}}}}=\frac{1}{\sqrt{\frac{1}{48}}},
\end{aligned}
$$




$$
\begin{aligned}
& \frac{1}{\sqrt{\lambda_{S_{2}}}}=\frac{1}{\sqrt{\frac{1769472 k_{1}+17644 k_{2}+7296 k_{1} k_{2}+2304 \sqrt{k_{1}^{2} k_{2}^{2}+3 k_{1}^{2} k_{2}+9 k_{1}^{2}+3 k_{1} k_{2}^{2}-9 k_{1} k_{2}+9 k_{2}^{2}}+36864}{1179648 k_{1}+1179648 k_{2}+737280 k_{1} k_{2}+1769472}}}, \\
& \frac{1}{\sqrt{\lambda_{S_{3}}}}=\frac{1}{\sqrt{\frac{1769472 k_{1}+17644 k_{2}+7296 k_{1} k_{2}-2304 \sqrt{k_{1}^{2} k_{2}^{2}+3 k_{1}^{2} k_{2}+9 k_{1}^{2}+3 k_{1} k_{2}^{2}-9 k_{1} k_{2}+9 k_{2}^{2}}+36864}{1179648 k_{1}+1179648 k_{2}+737280 k_{1} k_{2}+1769472}}} .
\end{aligned}
$$

The equivalent concentrated mass $m_{z}$ depended on the non-dimensional parameter of rotational stiffness $k_{1}$ and $k_{2}$ of the semi-rigid joint in the three-span girder was determined for the second and third mode of the vibrations by comparing the natural frequencies obtained by the stiffness method and the force method in accordance with the Eq. (13). The dependence of a change in the equivalent concentrated mass $m_{z}$ as a function of the non-dimensional parameter of the joint stiffness in the three-span girder is illustrated in Fig. 16.

In the three-span girder with semi-rigid joints between the spans, the first mode of vibration frequencies was constant and corresponded to the frequency of vibrations in the simply supported beam. But the second and third frequencies were changed. Thus, a change in the equivalent concentrated mass $m_{z}$ was only observed at the second and third mode of vibrations. A change in the equivalent concentrated mass $m_{z}$ was within a relatively narrow range for both the second and third mode of vibrations. It began at the point common for both modes of vibrations which specified the equivalent concentrated mass equal to the concentrated mass of the simply supported beam $m_{z}=17 / 35 \mu$ (the simply supported beam at the joint stiffness $k_{1}$ and $k_{2}=0$ ). When the stiffness of connections between the spans approached

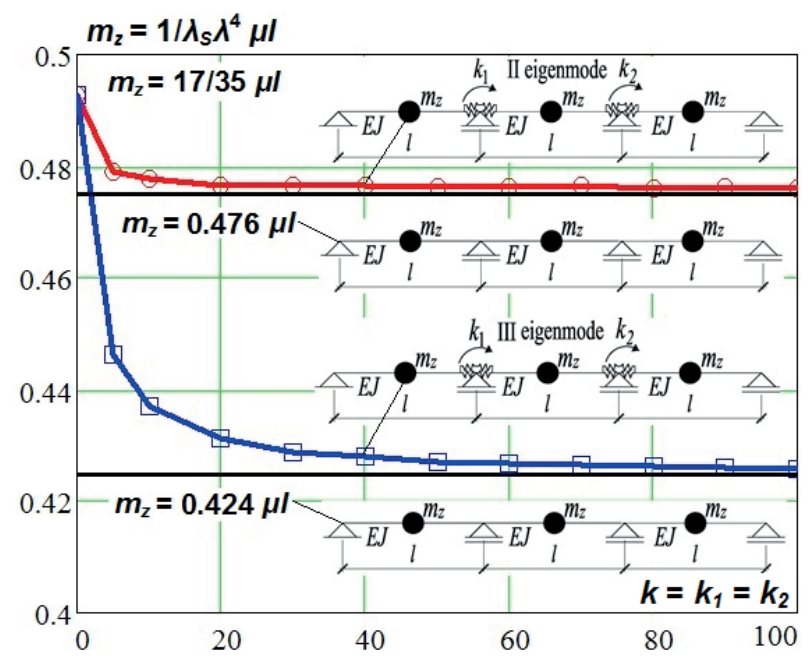

Fig. 16 Change of the equivalent concentrated mass $m_{z}$ in a three-span girder with semi-rigid joints between spans vs stiffness $k$ infinity, that is, $k_{1}$ and $k_{2}=\infty$, then at the second mode of vibrations the equivalent concentrated mass reached the value $m_{z}=0.476 \mu \mathrm{l}$, and the third mode $m_{z}$ was $0.424 \mu \mathrm{l}$. It means only a $2 \%$ change for the second mode of vibrations, and a $15 \%$ change for the third mode of vibrations.

The equivalent mass $m_{z}$ for the second mode of vibrations was rapidly changed, and reached the value of $0.48 \mu \mathrm{l}$, which practically meant the full stiffness of the spans, at stiffness $k_{1}$ and $k_{2}=5$. A change was much gentler for the third mode of vibrations. But at the joint stiffness $k_{1}$ and $k_{2}=5$, the equivalent concentrated mass $m_{z}$ reached $0.446 \mu \mathrm{l}$ constituting $2 / 3$ of the change interval range, and reached $0.431 \mu \mathrm{l}$ at stiffness $k_{1}$ and $k_{2}=20$. A further change was slow and only at the joint stiffness $k_{1}$ and $k_{2}$ $=100$ it reached the limit value corresponding to the full continuity of the supports. Hence, as in the case of the single-span girder, a relatively low stiffness of the span connections allowed the use of the values $m_{z}$ corresponding to the beam of full continuity to calculate the natural frequencies in the discrete system. It should be mentioned that both the second and third mode of free vibrations in the threespan girders can create problems related to the occurrence of resonant of exceeded maximum displacements.

\section{Conclusions}

The bolted connections in the single- and multi-span girders affect the frequency of vibrations of the elements in steel structures. They also change the equivalent concentrated mass which directly affects the frequency of vibrations in the discrete systems. A small change in frequencies results in the significant changes in the rotational stiffness of joints. The reduced stiffness of semi-rigid joints reduces the frequency of vibrations in the girders. And an increased rotational stiffness of the semi-rigid joints increases vibrations, which are then stabilized at the level typical for the continuous beams

The experimental tests indicate that an increase in the joint stiffness by replacing the corrugated web with strips of the flat one caused a slight increase in both the joint stiffness and the natural frequencies. On the other hand, 
preloading of joints with geometrical imperfections of end plates (pw-cw and pw-pw joints in the girder BP) led to a rapid increase in the vibration frequencies at a significant increase in the rotational stiffness of the joint.

The experimental tests also showed that a slight material damping occurred in the single-span girders with semi-rigid joints at midspan. Damping vanished as the joint stiffness increased. Thus, the semi-rigid joints can serve as specific dampers of vibrations by adjusting the size of displacements. It particularly refers to the structures exposed to cyclic loads, e.g., blasts of wind.

A change in the equivalent concentrated mass directly affected the natural frequencies in the system $\omega$ when performing calculations for the discrete systems. While estimating the natural frequencies, it was necessary to include the equivalent concentrated mass of the girder in the total mass of the vibrating system.

\section{References}

[1] CEN "EN 1993-1-8 Eurocode 3 Design of steel structures - Part 1-8: Design of joints", European Committee for Standardization, Brussels, Belgium, 2003.

[2] Chen, W.-F., Kishi, N. "Semirigid Steel Beam-to-Column Connections: Data Base and Modelling", Journal of Structural Engineering, 115(1), pp. 105-119, 1989. https://doi.org/10.1061/(ASCE)0733-9445(1989)115:1(105)

[3] Frye, M. J., Morris, G. A. "Analysis of Flexibly Connected Steel Frames", Canadian Journal of Civil Engineering, 2(3), pp. 280-291, 1975.

https://doi.org/10.1139/175-026

[4] Kozłowski, A. "Nośność belki z montażowymi węzłami podatnymi" (Load capacity of a beam with assembly semi-rigid joints), $\mathrm{PhD}$ Thesis, Instytut Techniki Budowlanej, 1988. (in Polish)

[5] Nethercot, D. A. "Steel Beam to Column Connections - A Review of Test Data and Their Applicability to the Evaluation of the Joint Behaviour of the Performance of Steel Frames", CIRIA Project Study, The University of Sheffield, Sheffield, UK, 1995.

[6] Basiński, W. "Wyznaczanie sztywności obrotowej doczołowych połączeń podatnych $\mathrm{w}$ metalowych konstrukcjach prętowych na podstawie pomiaru drgań" (Determination of the rotational stiffness of semirigid end joints in metallic structures based on the measured vibrations), $\mathrm{PhD}$ Thesis, Silesian University of Technology, 2006. (in Polish)

[7] Basiński, W. "Analysis of oscillatory motion of SIN girders with semirigid joints", Architecture Civil Engineering, Environment, 9(4), pp. 55-65, 2016.

[8] Chmielewski, T., Zembaty, Z. "Podstawy dynamiki budowli" (Basics of building dynamics), Arkady, Warszawa, Poland, 1988. (in Polish)

[9] Kowal, Z. "Dynamika nieważkiej belki na podporach lepkosprężystych" (The dynamics of a weightless beam on viscoelastic supports), Archives of Civil Engineering, XII(1), pp. 29-42, 1966. (in Polish)
Due to the possible formation of the mechanism, the range of a change in the equivalent concentrated mass $m_{z}$ was very broad in the single-span girders with the semirigid joints. While in the girder fixed at both ends, the interval of changes significantly dropped. However, it was characteristic that the joints with relatively small stiffness stabilized the value $m_{z}$ at the level which slightly differed from the girders with rigid joints.

In the three-span girders with the semi-rigid joints, the natural frequencies at mode 2 and 3 were changed which led to a change in the concentrated mass $m_{z}$. However, this change was very limited, and even small stiffness in the span connections allowed the use of the value $m_{z}$ corresponding to the beam of full continuity to calculate the natural frequencies in the three-span discrete system.

[10] Langer, J. "Dynamika budowli" (The dynamics of the building), Wroclaw University of Technology Publishing House, Wrocław, Poland, 1980. (in Polish)

[11] Attarnejad, R., Pirmoz, A. "Nonlinear analysis of damped semirigid frames considering moment-shear interaction of connections", International Journal of Mechanical Sciences, 81, pp. 165-173, 2014. https://doi.org/10.1016/j.jimecsci.2014.02.016

[12] Chan, S. L. "Vibration and modal analysis of steel frames with semirigid connections", Engineering Structures, 16(1), pp. 25-31, 1994. https://doi.org/10.1016/0141-0296(94)90101-5

[13] Galvão, A. S., Silva, A. R. D., Silveira, R. A. M., Gonçalves, P. B. "Nonlinear dynamic behavior and instability of steel frames with semi-rigid connections", International Journal of Mechanical Sciences, 52, pp. 1547-1562, 2010. https://doi.org/10.1016/j.ijmecsci.2010.07.002

[14] Kawashima, S., Fujimoto, T. "Vibration analysis of frames with semi-rigid connections", Computer and Structures, 19(1-2), pp. 85-92, 1984.

https://doi.org/10.1016/0045-7949(84)90206-2

[15] Sophianopoulos, D. S. "The effect of joint flexibility on the free elastic vibration characteristics of steel plane frames", Journal of Constructional Steel Research, 59(8), 995-1008, 2003.

https://doi.org/10.1016/S0143-974X(03)00004-X

[16] Kowal, Z., Malec, M. "Wyznaczanie nośności krytycznej swobodnie podpartych belek podsuwnicowych na podstawie pomiaru częstotliwości drgań własnych" (Determination of the critical load capacity of simply supported crane beams based on the measurement of the natural frequency), Inżynieria i Budownictwo, 2, pp. 51-53, 1989. (in Polish)

[17] Rakowski, G., Borkowski, A., Branicki, C., Ciesielski, R., Gomuliński, A., Kączkowski, Z., Langer, J., Olszowski, B., Przybyło, W., ..., Witkowski, M. "Mechanika Budowli z Elementami Ujęcia Komputerowego" (Structural Mechanics with Components of the Computer Shot), Arkady, Warszawa, Poland, 1972. (in Polish) 
[18] Basiński, W., Kowal, Z., Obara, P. "Diagnostyczne oszacowanie sztywności zamocowania dźwigarów stalowych" (Diagnostic assessment of the stiffness of steel girders), 55 Konferencja Naukowa Komitetu Inżynierii Lądowej i Wodnej PAN i Komitetu Nauki PZiTB "Krynica 2009", Kielce-Krynica, Poland, 2009, pp. 111-118. (in Polish)

[19] Easley, J. T. "Buckling formulas for corrugated metal shear diaphragms", Journal Structural Division, 101(7), pp. 1403-1417, 1975. https://doi.org/10.1061/JSDEAG.0004095

[20] Kuchta, K. "Sztywność i nośność blachownic o falistych środnikach" (Resistance and stiffness of plate girders with corrugated web), PhD Thesis, Technical University of Cracow, 2004. (in Polish)

[21] Moon, J., Yi, J., Choi, B. H., Lee, H.-E. "Shear strength and design of trapezoidally corrugated steel webs", Journal of Constructional Steel Research, 65(5), pp.1198-205, 2009. https://doi.org/10.1016/j.jcsr.2008.07.018

[22] Hassanein, M. F, Kharoob, O. F. "Behavior of bridge girders with corrugated webs: (II) Shear strength and design", Engineering Structures, 57, pp. 544-553, 2013.

https://doi.org/10.1016/j.engstruct.2013.04.015
[23] Basiński, W. "Shear buckling of plate girders with corrugated web restrained by end stiffeners", Periodica Polytechnica Civil Engineering, 62(3), pp. 757-771, 2018. https://doi.org/10.3311/PPci.11554

[24] Basiński, W. "Shear buckling resistance of cantilever girders with corrugated web", Architecture Civil Engineering, Environment, 9(1), pp. 63-79, 2019. https://doi.org/10.21307/ACEE-2019-006

[25] Department of Steel Structures and Welding "Profile z falistym środnikiem SIN. Zasady wymiarowania" (Profiles of corrugated web of SIN girders. Principles of dimensioning), Cracow University of Technology, Cracow, Poland, 2002. (in Polish)

[26] CEN "EN 1993-1-5, Eurocode 3 - Design of steel structures Part 1-5: Plated structural elements", European Committee for Standardization, Brussels, Belgium, 2008. 